\title{
Speech and language profiles in 4- to 6-year-old children with early diagnosis of autism spectrum disorder without intellectual disability
}

This article was published in the following Dove Press journal:

Neuropsychiatric Disease and Treatment

\author{
Liselotte Kjellmer ${ }^{1,2}$ \\ Elisabeth Fernell ${ }^{2}$ \\ Christopher Gillberg ${ }^{2}$ \\ Fritjof Norrelgen ${ }^{2-4}$ \\ 'Department of Special Education, \\ Stockholm University, Stockholm, \\ Sweden; ${ }^{2}$ Gillberg Neuropsychiatry \\ Centre, Institute of Neuroscience \\ and Physiology, Sahlgrenska Academy, \\ Gothenburg University, Gothenburg, \\ Sweden; ${ }^{3}$ Functional Area Speech \\ and Language Pathology, Karolinska \\ University Hospital, Stockholm, \\ Sweden; ${ }^{4}$ Department of Clinical \\ Neuroscience, Karolinska Institutet, \\ Stockholm, Sweden
}

Purpose: This study aimed to present speech and language data from a community-representative group of 4- to 6-year-old children with early-diagnosed autism spectrum disorder (ASD) without intellectual disability (ID).

Methods: The study group comprised 83 children 4-6 years of age with ASD without ID. They had been diagnosed with ASD before age 4.5 years and had received intervention at a specialized habilitation center. At 2-year follow-up, their language abilities were evaluated comprehensively by two speech-language pathologists using a battery of assessments. Receptive and expressive language and phonology were examined. The phonology evaluation included measures of phonological speech production and of phonological processing.

Results: Results revealed that almost $60 \%$ had moderate-severe language problems. Nearly half exhibited combined expressive and receptive language problems, of which a majority also had phonology problems. Phonological speech problems were found in $21 \%$ of the total group.

Conclusion: The findings underscore the importance of considering speech/language disorders in children with ASD without ID, since they usually attend mainstream classes but need specific educational adaptations.

Keywords: autism spectrum disorder, language, speech, language disorders, speech-language pathology

\section{Introduction}

Language impairments in children with autism spectrum disorders (ASD) are common, but knowledge of the specific nature of these disorders is still limited. ${ }^{1-3}$ Children with ASD often exhibit impairments in receptive and/or expressive structural language, ie, difficulties understanding and/or formulating language. Structural language comprises the domains of semantics, which includes vocabulary and word relations, and grammar. Several studies of language skills in young children with autism have reported more impaired receptive than expressive language ability, 4,5 but others have found the reverse pattern..$^{6-8}$ A meta-analysis has concluded that receptive and expressive language may be equally impaired. ${ }^{9}$ Other studies have not investigated the relative relationship, but have demonstrated receptive and expressive language impairments in children with ASD and also in individuals who do not have intellectual disability (ID). ${ }^{10-12}$ However, within the group of children with ASD, receptive and expressive language abilities vary a lot, not just across the IQ spectrum but also within the group of children with ASD without ID. For example, Chan et al ${ }^{12}$ and Kjellmer et $\mathrm{al}^{13}$ both found impaired sentence comprehension in samples of children with ASD without ID. By contrast, Åsberg ${ }^{14}$ found that school-age children with ASD without ID
Correspondence: Liselotte Kjellme Department of Special Education, Stockholm University, Stockholm 106 91, Sweden

Tel +46 72 |4| 0277

Email liselotte.kjellmer@specped.su.se 
performed as well as typically developing peers on word and sentence comprehension, but had impaired narrativediscourse comprehension. Moreover, a relatively large proportion of children with ASD without ID likely exhibit neither receptive nor expressive language problems. ${ }^{10-12}$ To some degree, the variable results across studies can be explained by methodological factors, such as types of ASD subgroups included in the samples, presence of associated disorders, various assessment protocols used, and different cutoffs and classifications of language problems. Research on profiles of language abilities in children with ASD without ID is not only variable, but it is also still scant, ${ }^{3,12}$ and samples often include children both with and without ID. As such, this review pertaining to domain-specific language performance of children with ASD includes studies comprising children across the IQ spectrum, unless otherwise specified.

In addition to the language domains of semantics and grammar, the domain of phonology will be reviewed. As will be evident herein, phonology is another language domain in which children with ASD with or without ID may demonstrate impairment. Phonology may encompass both phonological speech production and phonological processing. Phonological speech production concerns speech-sound patterns and contrasts of a language, and is thus a linguistic (or "language") aspect of speech. ${ }^{15}$ To exemplify phonological speech-sound error patterns, a child might exhibit a pattern of "fronting". This error pattern implies substituting rear consonants (eg, $/ \mathrm{k} / \mathrm{g} /)$ with front consonants $(/ \mathrm{t} / \mathrm{d} /)$, such that the word "cup" would be pronounced "tup". Another example is an error pattern of "consonant-cluster reduction", such that "truck" would be pronounced "tuck". Phonological speech problems may make it hard to understand what the child is saying. It might be confusing that phonological speech production simultaneously be viewed as an aspect of the language domain of phonology and as an aspect of speech. Another, nonlinguistic aspect of speech is articulation, which concerns the motor movements needed to produce speech sounds. ${ }^{15}$ Lisping of $/ \mathrm{s} /$ is an example of an articulation error. Articulation was not examined in the current study. The language domain of phonology also includes phonological processing, as mentioned. Phonological processing concerns the ability to perceive, analyze, remember, and manipulate the sound structures of words. ${ }^{16}$ Problems with phonological processing are mainly detected through specific tasks, such as repetition of nonwords (ie, nonsense words).

In the domain of semantics, studies of vocabulary development measured by parent report have found that it is generally delayed in many preschool children with ASD, including children without ID, when compared to age norms, ${ }^{17}$ as well as to children matched for nonverbal mental age. ${ }^{4,18}$ In addition, vocabulary development has been shown to be impaired in children in preschool and school-age ranges when assessed through formal testing. ${ }^{10}$ In contrast, Eigsti et $\mathrm{al}^{2}$ reported that several studies have found children with ASD perform as well as typically developing children matched for mental age on vocabulary tests. They further reviewed studies examining other types of semantic tasks. Those studies showed that children with ASD perform as well as typically developing peers on basic word-categorization tasks, but have difficulties with some specific aspects of semantic comprehension, such as comprehension of mentalstate verbs and with semantic organization.

Studies of development of grammatical skills in children with ASD have presented somewhat contradictory results. For example, it has been reported that grammar may be a relative strength ${ }^{19}$ and if problems exist, they are limited to those children who have general language impairment. ${ }^{20}$ Moreover, Diehl et $\mathrm{a}^{21}$ found that syntactic ability assessed by a paradigm using prosody vs syntactic contrast was unimpaired in adolescents with ASD. However, a number of studies have reported delayed acquisition of grammatical morphemes in children with $\mathrm{ASD},{ }^{22-25}$ which to some extent has been interpreted by the authors as signifying a broader problem with grammar. Performance on grammatical judgment of incorrect/correct sentences has shown children with ASD to be less sensitive than controls. ${ }^{2,26}$ In some of the more recent research on this matter, there seems to be agreement that development of grammar generally may be delayed in children with ASD. ${ }^{3}$

As for the language domain of phonology, phonological speech production and phonological processing in ASD have been assessed in a large number of studies employing different methods and problem definitions. Age and ASDsubgroup-composition characteristics, as well as classifications of assessment outcomes and the ensuing conclusions, have varied considerably among studies. A review of previous research is beyond the scope of this article, but a few more recent studies are briefly presented here. For example, Rapin et $\mathrm{al}^{27}$ analyzed language data of children with ASD, and reported more than a quarter of the group as having phonological speech problems. In comparison, Cleland et a ${ }^{28}$ found speech problems in $12 \%$ when assessing a group of children with ASD without ID; however, $41 \%$ of the children produced at least some speech errors. Of note, in the Cleland et al study, phonological speech errors and articulatory speech errors were not separated in the analyses; however, 
the majority of speech errors found were described as being phonological in nature. Although the main focus in a study by Shriberg et al $^{29}$ was to investigate childhood apraxia of speech in children with ASD without ID aged 4-7 years, they also assessed speech broadly. Shriberg et al reported "speech delay", defined as mainly phonological speech errors affecting intelligibility (but also including articulation errors) occurring in $15 \%$ of their sample. Studies investigating phonological processing in ASD have often included individuals with ASD plus language impairment (ALI), comparing their performance to that of individuals with specific language impairment (SLI). For example, phonological processing in adolescents with ALI, SLI, or who were typically developing was assessed by Riches et $\mathrm{al}^{30}$ using nonword repetition. Their results, replicating those of another study, ${ }^{31}$ showed performance in participants with ALI to be poorer than in typically developing participants, and poorer in SLI than in ALI. The latter finding was mainly explained by lower phonological working memory in the SLI group. Another study of nonword repetition by Williams et $\mathrm{a}^{32}$ compared performance of children with SLI or ALI with that of typically developing children matched for chronological age or verbal mental age, respectively. They discovered lower performance in SLI than in ALI, similar performance in children with ALI and language-matched typically developing children, and lower performance in ALI than in chronologically age-matched peers. To summarize, earlier studies have not been conclusive regarding this topic. More recent studies suggest that phonological speech problems are more common in children with ASD than in typically developing children, although the mechanisms behind the problems and their precise nature remain unclear. Moreover, individuals with ALI show poorer phonological processing than typically developing peers, but better ability than individuals with SLI.

An aspect of general importance to consider is the relationship between language and general cognitive ability. As might be expected, language ability is clearly related to IQ when examining children with ASD inclusive of all IQ levels. ${ }^{10,17}$ Indeed, the most important prognostic factors for developing spoken language in children with ASD have been reported to be overall cognitive level and early milestones in language development. ${ }^{33-35}$ The importance of assessing both general cognitive level and language abilities in children with ASD has been underscored, given that the child's intellectual level can be more significant for language development than the severity of the autistic symptoms. ${ }^{17}$ Unexpectedly, however, for individuals with ASD and IQ within the normal range, the relationship between language ability and IQ may not be as strong. For example, Kjellmer et $\mathrm{al}^{13}$ reported that nonverbal IQ could explain only $10 \%$ of the variation in sentence-comprehension scores, and as previously mentioned, several studies have found clinically significant language impairment and normal language, respectively, within this group. ${ }^{3}$

Taken together, these findings reveal that it is evident that several different types of language problems, including problems with phonological speech production and phonological processing, are frequent in children with ASD, but that information about the specific nature and interrelationships of these problems is still limited. In particular, knowledge about how the problems manifest in children with ASD without ID is still scarce in community-representative samples.

The aim of the present study was to investigate the language profiles, also including phonology (ie, phonological speech production and phonological processing), in a relatively large community-representative group of 4- to 6-year-old children with early-diagnosed ASD without ID. The following research questions were asked: To what extent do children with early-diagnosed ASD without ID display language problems?; What language profiles do children with early-diagnosed ASD without ID exhibit with regard to receptive language, expressive language, and phonology abilities?; What differences, if any, are there between ASD subgroups?; and What is the relationship between language variables and performance and verbal IQ (PIQ and VIQ) in children with early-diagnosed ASD without ID?

\section{Methods \\ Participants}

Participants were selected from a community-representative cohort of 208 Swedish preschool children with ASD. This cohort is described in detail elsewhere. ${ }^{36,37}$ In brief, all 208 children with ASD were enrolled at a specialized habilitation center, the Autism Center for Young Children (ACYC), before 4.5 years of age to receive early interventions. Research data were collected at enrollment and again after 2 years. Data used here were collected at the 2-year follow-up, at which time the children were comprehensively assessed by a research team consisting of experienced physicians (two neuropediatricians, one pediatrician, and one child neuropsychiatrist), psychologists, and speech-language pathologists. $^{37}$

All children in the cohort not meeting criteria for ID were targeted for inclusion in the current study. Inclusion criteria were IQ within the "normal range", ie, full-scale IQ $\geq 70$ measured by the Wechsler Preschool and Primary Scale of 
Intelligence III. ${ }^{38}$ Two of the children had been assessed outside the center and were considered to be clearly within the normal range; however, exact IQ scores were not available. Two other children fell just below the IQ limit, but based on the overall clinical assessment, including adaptive functioning, were not considered to fulfill criteria for mild ID and were included. Altogether, 101 children were classified as not having ID. Seven families chose not to let their child participate in the language-testing part of the follow-up. Of the children who did participate in the language testing, Swedish was not the first language in eleven children, who were thus excluded. The final study group consisted of 83 children - 75 boys and eight girls (male:female 9:1) - and the group's mean full-scale IQ ( $\mathrm{n}=82)$ was 88.8 (SD 14.2). The chronological age range of the sample at language testing, was 4.0-6.8 years (mean 5.9 years, SD 0.7). Language testing was administered shortly after the cognitive assessment. According to Diagnostic and Statistical Manual of Mental Disorders, 4 th edition (DSM-IV) criteria, ${ }^{39}$ used at the time of assessment, the distribution of ASD subgroups was: autistic disorder ( $A D ; n=20,24 \%$ ), pervasive developmental disorder-not otherwise specified (PDD-NOS; $n=37,45 \%$ ), and Asperger's syndrome (AS; $\mathrm{n}=12,15 \%)$. In addition, children who had been referred to the center with a diagnosis of ASD and at the time of the 2-year follow-up did not meet full criteria, but had "autistic features" (AFs; n=14, 17\%), were included. ${ }^{37}$ Table 1 shows the distribution of IQ scores by ASD subgroup.

\section{Measures and procedure}

The 83 children were assessed with a battery of language tests administered by two experienced speech-language research pathologists. Testing was conducted in one 1.5hour session and took place in a quiet room at the ACYC. The test battery consisted of tests for sentence comprehension (Reynell Developmental Language Scale [RDLS] III), ${ }^{40}$ word comprehension (Snabbt Performancetest på Intelligence (IQ) [SPIQ]), ${ }^{41}$ word analogies (subtest from the Illinois Test of Psycholinguistic Abilities [ITPA]), ${ }^{42}$ grammar (Processability Test [PT]), ${ }^{43}$ and phonological processing (nonword-repetition task [NWRT]). ${ }^{44}$ In addition, phonological speech-production assessment (PSPA) was conducted, based on analysis of recordings from the language assessment. In particular, PSPA encompassed structured clinical phonological speech-error analysis (ie, speechsound-pattern errors, not motor-based articulation errors) performed on recordings of the PT and of a retelling task (Bus Story Test). ${ }^{45,46}$ The retelling task was not used in any other analyses of the current study. Recordings of each child were coded independently for phonological speech errors by the two speech-language research pathologists using a structured protocol. All mispronounced words were listed, and types of phonological speech errors applying to each word were noted. Each child's phonological speech production was then classified into one of three categories: no phonological speech problems, ie, no examples of phonological speech-sound-error patterns found or isolated examples of incorrectly pronounced words; minor phonological speech problems, ie, examples of two to four non-age-appropriate phonological speech-sound-error patterns, ${ }^{47,48}$ but not consistently occurring; and definite phonological speech problems, ie, examples of either five or more non-age-appropriate phonological speech-sound-error patterns or fewer than five error patterns, but multiple examples of each or examples of a clearly deviant error pattern (eg, backing, "top" $\rightarrow$ "cop"). To be classified as definite phonological speech problems, the mispronunciations also had to have negative effects on the intelligibility of the speech and clinically there was no doubt about phonological speech problems. After all children had been classified (except two, who were excluded), coders compared their classifications. Point-by-point (based on classification code) interrater reliability was 0.79 . For those children where phonological speech-production classification differed between coders, consensus was subsequently reached through discussion. Phonological speech-error analysis was used, since no standardized Swedish tests of phonological speech production were available at the time of the study.

A child's performance on a language measure was classified as being in the impaired range if it was below a set criterion for that specific measure. Standard scores used

Table I VIQ and PIQ scores divided by ASD subgroup

\begin{tabular}{llllll}
\hline & AD $(\mathbf{n}=\mathbf{2 0})$ & $\begin{array}{l}\text { PDD-NOS } \\
(\mathbf{n}=\mathbf{3 6})\end{array}$ & AS $(\mathbf{n}=\mathbf{1 2})$ & \multicolumn{1}{|c}{$\begin{array}{l}\text { AFs } \\
(\mathbf{n}=\mathbf{1 4})\end{array}$} & $\begin{array}{l}\text { Total group } \\
(\mathbf{n}=\mathbf{8 2})\end{array}$ \\
\hline $\mathrm{VIQ}$ & $82.7(14.7)$ & $86.4(14.1)$ & $99.0(13.2)$ & $95.1(7.0)$ & $88.8(14.2)$ \\
PIQ & $90.8(15.3)$ & $98.0(12.8)$ & $102.0(19.0)$ & $101.6(11.2)$ & $97.4(14.6)$ \\
\hline
\end{tabular}

Abbreviations: VIQ, verbal IQ; PIQ, performance IQ; ASD, autism spectrum disorder; AD, autistic disorder; AFs, autistic features; AS, Asperger's syndrome; PDD-NOS, pervasive developmental disorder-not otherwise specified; IQ, Intelligence quotient. 
reflected clinically relevant ones given in the test manuals. In particular, impaired range was defined as $<10$ th percentile on the RDLS, below stanine 3 on the SPIQ and word analogies (ITPA), and $<-1.25 \mathrm{SD}$ on the NWRT. That is, criteria for these four measures all equaled (approximately) $1.25 \mathrm{SD}$ below the mean, a commonly used and recommended cutoff in studies of language disorder. ${ }^{49}$ The PT, based on processability theory ${ }^{50}$ is a screening test of grammar assessing seven grammatical structures corresponding to five developmental levels. The processability theory proposes that language acquisition requires "procedural skills" needed to process grammatical structures. According to the theory, the development of grammatical structures follows a specific sequence, in which the lower level procedural skills are necessary for the following higher levels. Typically developing children are expected to master the highest level, ie, level 5 , at 3.5 years of age ${ }^{51}$ The impaired-range criterion for the PT was thus set to performance below level five or performance at level five, but with less than six grammatical structures passed. For PSPA, a classification of "definite phonological speech problems" was considered performance within the impaired range. Performance in the impaired range on two or more of the language measures was here defined as moderate-severe language problems, in the impaired range on one of the measures as mild language problems, and performance in the unimpaired range on all measures as no language problems.

All children were assessed with word analogies (ITPA); however, since norms start at 5 years, results for children younger than this age were treated as missing data $(n=17)$. On the NWRT, five children did not participate. For two children, data from the PT were missing. One child's grammatical ability was considered age-appropriate when scrutinizing recordings of spontaneous speech and the same retelling task used for PSPA, ie, the "Bus Story Test". For the other child, another grammatical test (GRAMBA [Grammatiktest för Barn] $)^{52}$ had been conducted and performance considered age-appropriate (stanine 3). Two children had been excluded from PSPA. One of the children had pervasive glottal articulation, due to velopharyngeal insufficiency. This child's phonological speech production was categorized as being in the impaired range (ie, corresponding to "definite phonological speech problems"), even though the speech problems were associated with anatomically structural difficulties and could have been of both phonological speech production and a motor-based articulation nature. The other child did not participate in either of the two tasks used for PSPA, and was thus excluded from the impaired-range analysis of this measure.

To explore language profiles, the six language measures were grouped to represent a receptive language factor (sentence and word comprehension), an expressive language factor (word analogies and grammar), and a phonology factor (phonological speech production and phonological processing; Table 2). A child was considered to fail on a factor if performance on at least one of the two measures included in that factor was in the impaired range. The expressive language factor was based on the PT alone for the 4-year-olds, since their data on word analogies were treated as missing. For the two children lacking data on the PT, the grammar component of the expressive factor was considered unimpaired based on other information. As previously explained, one child was excluded from the impaired-range analysis of PSPA. As this child had not participated in the NWRT either, the language profile for this child was based solely on the receptive and the expressive factors.

\section{Data analysis}

In descriptive data analyses, scores considered clinically relevant and given in test manuals were used, ie, standard scores for VIQ and performance IQ (PIQ), percentiles for sentence comprehension (RDLS), stanine scores for word comprehension (SPIQ), word analogies (ITPA), and $z$-scores for the phonological processing task (NWRT). For the grammar test (PT) and PSPA, percentage distribution by processibility level accomplished and by classification category, respectively, was used.

Table 2 Specifications of measures and measure-specific impaired-range cutoffs or definitions per language factor

\begin{tabular}{lll}
\hline & Measures & Impaired-range cutoff \\
\hline Receptive language & RDLS (sentence comprehension) & $<$ Percentile I0 \\
& SPIQ (word comprehension) & $<$ Stanine 3 \\
Expressive language & ITPA (word analogies) & $<$ Stanine 3 \\
& PT (grammar) & $<$ Level 5 or at level 5 but $<6$ structures \\
Phonology & PSPA (phonological speech production) & Classification of "definite phonological speech problems" \\
\hline
\end{tabular}

Abbreviations: ITPA, Illinois Test of Psycholinguistic Abilities; NWRT, nonword-repetition task; PT, Processability Test; PSPA, phonological speech-production assessment; RDLS, Reynell Developmental Language Scale; SPIQ, Snabbt Performancetest på Intelligence (IQ). 
In inferential data analyses of ASD-subgroup differences, the same scoring was used, except for the RDLS, for which $z$-scores were used to achieve a less skewed distribution. Parametric ANOVAs and Tukey's post hoc test were used in analyses of ASD subgroup differences on RDLS and NWRT results. For the corresponding analyses on the SPIQ, word analogies, PT, and PSPA, Kruskal-Wallis was used with $\chi^{2}$ post hoc analyses. In analyses of relationships between VIQ and PIQ, respectively, vs RDLS, SPIQ, word analogies, and NWRT, Pearson correlations were conducted. For corresponding analyses of the PT and PSPA, Spearman correlations were calculated.

\section{Ethical approval}

All parents provided oral informed consent for their children to participate in the study, which was approved by the Regional Ethics Committee in Stockholm (approval number 2006/61-31/2).

\section{Results}

\section{Language problems}

Moderate-severe language problems were found in 59\% of the children in the total ASD group ( $\mathrm{n}=49$; AD 14, PDD-NOS 28, AS 1, AFs 6). Mild language problems were found in $24 \%$ $(\mathrm{n}=20$; AD 5, PDD-NOS 4, AS 6, AFs 5) and no language problems in 17\% ( $\mathrm{n}=14$; AD 1, PDD-NOS 5, AS 5, AFs 3$)$ of the children. Of the total group, $21 \%$ (17 children) exhibited definite phonological speech problems, ie, clinically relevant speech-sound-pattern errors present in their speech. All of these children demonstrated moderate-severe language problems. Results on all language measures for the total group and divided by ASD subgroup are shown in Table 3. Table 4 reports the proportions of children performing in the impaired range (defined in the Methods section) on each language measure for the whole group and per ASD subgroup.

\section{Language profiles}

Language profiles were analyzed in the total ASD group and the ASD subgroup (Table 5). Results revealed that $46 \%$ of the total ASD group failed on both the receptive and expressive language factors. A majority of those children (29\% of the total ASD group) also failed on the phonology factor, ie, displaying a combination of receptive and expressive language problems, as well as phonology problems. No child with AS showed this type of comprehensive language-problem profile, whereas the AD, PDD-NOS, and AF subgroups were represented to a relatively high extent. An additional proportion of the children failed on either the

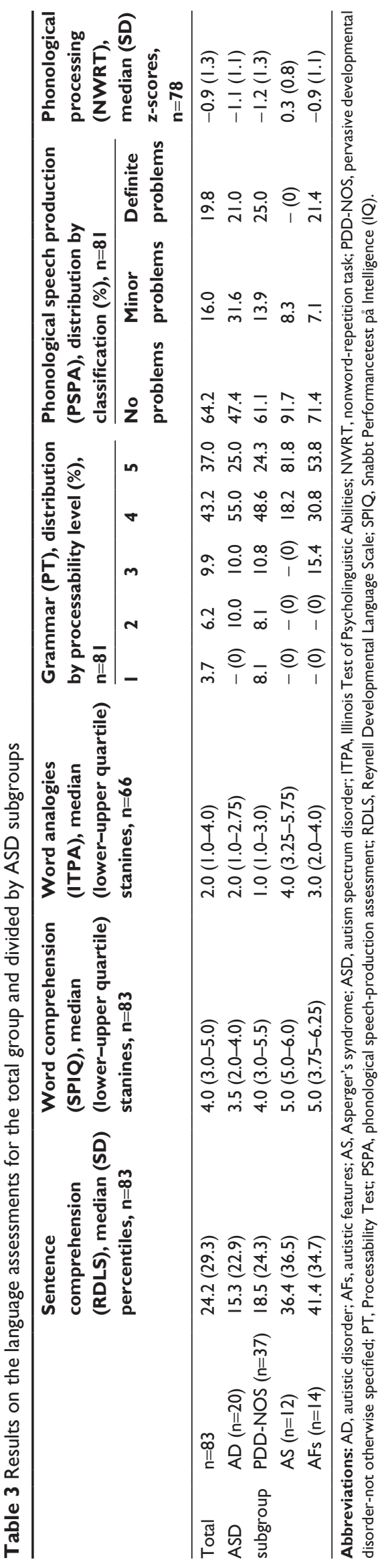


Table 4 Percentage within impaired range on each language measure for the total group and divided by ASD subgroups

\begin{tabular}{|c|c|c|c|c|c|c|c|}
\hline & & \multicolumn{2}{|c|}{ Receptive language } & \multicolumn{2}{|c|}{ Expressive language } & \multicolumn{2}{|l|}{ Phonology } \\
\hline & & $\begin{array}{l}\text { Sentence } \\
\text { comprehension } \\
\text { (RDLS), } \mathbf{n}=\mathbf{8 3}\end{array}$ & $\begin{array}{l}\text { Word } \\
\text { comprehension } \\
\text { (SPIQ), n=83 }\end{array}$ & $\begin{array}{l}\text { Word } \\
\text { analogies } \\
\text { (ITPA), n=66 }\end{array}$ & $\begin{array}{l}\text { Grammar } \\
\text { (PT), n=8 I }\end{array}$ & $\begin{array}{l}\text { Phonological } \\
\text { speech production } \\
\text { (ASPA), } n=82\end{array}$ & $\begin{array}{l}\text { Phonological } \\
\text { processing } \\
\text { (NWRT), n=78 }\end{array}$ \\
\hline Total & $n=83$ & 53 & 16 & 52 & 64 & 21 & 41 \\
\hline ASD & $A D(n=20)$ & 60 & 45 & 75 & 80 & 21 & 39 \\
\hline \multirow[t]{3}{*}{ subgroup } & PDD-NOS ( $n=37)$ & 59 & 11 & 62 & 76 & 27 & 53 \\
\hline & AS $(n=12)$ & 42 & 0 & 0 & 18 & 0 & 8 \\
\hline & AFs $(n=14)$ & 36 & 0 & 44 & 46 & 21 & 43 \\
\hline
\end{tabular}

Abbreviations: AD, autistic disorder; AFs, autistic features; AS, Asperger's syndrome; ASD, autism spectrum disorder; ITPA, Illinois Test of Psycholinguistic Abilities; NWRT, nonword-repetition task; PT, Processability Test; PSPA, phonological speech-production assessment; PDD-NOS, pervasive developmental disorder-not otherwise specified; RDLS, Reynell Developmental Language Scale; SPIQ, Snabbt Performancetest på Intelligence (IQ).

expressive factor $(24 \%)$ or the receptive factor $(10 \%)$ with or without also failing the phonology factor. All ASD subgroups were represented to a fairly high extent in the former type of language profile. Considering the latter, the AS group stood out, as $42 \%$ of children with AS exhibited this type of language profile. In the total ASD group, $4 \%$ failed the phonology factor only, represented by two children with AFs and one with $\mathrm{AD}$. Of the $29 \%$ of children presenting a language profile of receptive language, expressive language, and phonology problems, about half ( $16 \%$ of the total ASD group) exhibited phonological speech problems. Further, of the 20 children with a language profile of combined expressive language and phonology problems, only three ( $4 \%$ of the total ASD group) demonstrated phonological speech problems. In contrast, the two children with combined receptive language and phonology problems demonstrated no phonological speech problems, but impaired phonological processing. Only one of the three children with a profile of just phonology problems demonstrated speech problems. As stated, $17 \%$ of the total ASD group did not fail on any of the factors.

\section{ASD-subgroup differences}

Inferential analyses of differences in test performance between ASD subgroups revealed the following results.

\section{Sentence comprehension (RDLS)}

A one-way ANOVA (based on $z$-scores) showed an overall difference among the subgroups $\left(F_{3,79}=4.074, P=0.010\right)$. Post-hoc analysis (Tukey's) showed this difference to be caused by the $\mathrm{AD}$ group performing worse than the $\mathrm{AF}$ group $(P=0.032)$.

\section{Word comprehension (SPIQ)}

There was a significant subgroup difference on Kruskal-Wallis testing $\left(H_{3}=14.56, P=0.002 ; \mathrm{n}=83\right)$. Post hoc analysis $\left(\chi^{2}\right)$ revealed that this derived from the $\mathrm{AD}$ group performing worse than the $\operatorname{AS}$ group $(P=0.004)$ and the $\operatorname{AF}$ group $(P=0.032)$.

Table 5 Language profiles based on receptive language, expressive language, and phonology factors for the total group and divided by ASD subgroup

\begin{tabular}{|c|c|c|c|c|c|c|}
\hline & Factors failed & $\begin{array}{l}\text { Total ASD } \\
\text { group, } n=83(\%)\end{array}$ & $\begin{array}{l}A D, \\
n=20(\%)\end{array}$ & $\begin{array}{l}\text { PDD-NOS, } \\
n=37(\%)\end{array}$ & $\begin{array}{l}\text { AS, } \\
n=12(\%)\end{array}$ & $\begin{array}{l}\text { AFs, } \\
n=14(\%)\end{array}$ \\
\hline \multirow[t]{5}{*}{ Collapsed } & Expressive + receptive \pm phonology & 45.8 & 70.0 & 54.0 & 0 & 28.6 \\
\hline & Expressive \pm phonology & 24.1 & 20.0 & 27.0 & 16.7 & 28.6 \\
\hline & Receptive \pm phonology & 9.6 & 0 & 5.4 & 41.6 & 7.1 \\
\hline & Phonology only & 3.6 & 5.0 & 0 & 0 & 14.3 \\
\hline & None & 16.9 & 5.0 & 13.5 & 41.7 & 21.4 \\
\hline \multirow[t]{8}{*}{ Detailed } & Receptive + expressive + phonology & 28.9 & 35.0 & 37.8 & 0 & 21.4 \\
\hline & Receptive + expressive & 16.9 & 35.0 & 16.2 & 0 & 7.1 \\
\hline & Expressive + phonology & 7.2 & 0 & 13.5 & 0 & 7.1 \\
\hline & Receptive + phonology & 2.4 & 0 & 2.7 & 8.3 & 0 \\
\hline & Expressive only & 16.9 & 20.0 & 13.5 & 16.7 & 21.4 \\
\hline & Receptive only & 7.2 & 0 & 2.7 & 33.3 & 7.1 \\
\hline & Phonology only & 3.6 & 5.0 & 0 & 0 & 14.3 \\
\hline & None & 16.9 & 5.0 & 13.5 & 41.7 & 21.4 \\
\hline
\end{tabular}

Abbreviations: AD, autistic disorder; AFs, autistic features; AS, Asperger's syndrome; ASD, autism spectrum disorder; PDD-NOS, pervasive developmental disorder-not otherwise specified. 
Table 6 Correlations and explained variance $\left(r^{2}\right)$ of VIQ and PIQ in relation to the language variables

\begin{tabular}{lllllll}
\hline & $\begin{array}{l}\text { Sentence } \\
\text { comprehension } \\
\text { (RDLS) }\end{array}$ & $\begin{array}{l}\text { Word } \\
\text { comprehension } \\
\text { (SPIQ) }\end{array}$ & $\begin{array}{l}\text { Word } \\
\text { analogies } \\
\text { (ITPA) }\end{array}$ & $\begin{array}{l}\text { Grammar } \\
\text { (PT) }\end{array}$ & $\begin{array}{l}\text { Phonological } \\
\text { speech production } \\
\text { (PSPA) }\end{array}$ & $\begin{array}{l}\text { Phonological } \\
\text { processing } \\
\text { (NWRT) }\end{array}$ \\
\hline VIQ: correlation & $0.626 * *$ & $0.563^{* *}$ & $0.8 I I^{* *}$ & $0.54 I^{* * *}$ & $-0.309 * * *$ & $0.302^{* *}$ \\
$r^{2}$ & 0.392 & 0.317 & 0.658 & 0.293 & 0.095 & 0.091 \\
$\mathrm{n}$ & 82 & 82 & 65 & 80 & 80 & 77 \\
PIQ: correlation & $0.396 *$ & $0.312^{* *}$ & $0.299 * *$ & $0.294^{* *}$ & -0.194 & $0.274^{*}$ \\
$r^{2}$ & 0.157 & 0.097 & 0.089 & 0.086 & 0.038 & 0.075 \\
$\mathrm{n}$ & 82 & 82 & 65 & 80 & 80 & 77 \\
\hline
\end{tabular}

Notes: $* P<0.05$ (Pearson, two-tailed); $* * P<0.01$ (Pearson two-tailed); $* * * P<0.01$ (Spearman, two-tailed).

Abbreviations: ITPA, Illinois Test of Psycholinguistic Abilities; NWRT, nonword-repetition task; PT, Processability Test; PSPA, phonological speech-production assessment; RDLS, Reynell Developmental Language Scale; SPIQ, Snabbt Performancetest på Intelligence (IQ).

\section{Word analogies (ITPA)}

A significant difference (Kruskal-Wallis) among subgroups was found $\left(H_{3}=17.90, P<0.001 ; \mathrm{n}=66\right)$, and post hoc analysis $\left(\chi^{2}\right)$ revealed that this was an effect of the AS group's better performance than the $\mathrm{AD}(P=0.004)$ and PDD-NOS $(P<0.001)$ groups.

\section{Grammar (PT)}

There was an overall difference (Kruskal-Wallis) between subgroups $\left(H_{3}=13.85, P=0.003 ; \mathrm{n}=81\right)$, and the post hoc analysis $\left(\chi^{2}\right)$ revealed that this was an effect of the AS group performing better than the $\mathrm{AD}(P=0.048)$ and PDD-NOS ( $P=0.008)$ groups.

\section{Phonological processing (NWRT)}

A one-way ANOVA (based on $z$-scores) showed that there was a difference between ASD subgroups $\left(F_{3,74}=5.122\right.$, $P=0.003)$ and that this was an effect of the AS group's better performance than the AD $(P<0.016)$ and PDD-NOS $(P<0.001)$ groups.

\section{Phonological speech production (PSPA)}

No significant difference (Kruskal-Wallis) among subgroups was discovered $\left(H_{3}=6.12, P=0.106 ; \mathrm{n}=81\right)$.

\section{Correlations between language and cognitive measures}

Table 6 shows correlations between all language measures and PIQ, as well as VIQ. Correlations with PIQ ranged between 0.19 and 0.40 , and were significant for all measures but PSPA. However, only $4 \%-16 \%\left(r^{2}\right)$ of the variation in the language-measure scores could be explained by PIQ. Correlations with VIQ were higher (0.30-0.81), and were significant for all measures. Still, only $10 \%-39 \%\left(r^{2}\right)$ of the variation in language-measure scores was able to be explained by VIQ, except for word analogies, which stood out with $66 \%$ of the variation being explained.

\section{Discussion}

Almost $60 \%$ of this community-based cohort of 4- to 6-yearold children with ASD of different severity and without ID had moderate-severe language problems. Only one in six of the 83 children had no such problems. ASD diagnoses had been based on the DSM-IV, used at the time of the study, and the children with AFs at this 2-year follow-up had met full criteria at the time of inclusion in the study. Subsequently, we conducted a more detailed analysis of language profiles, using the receptive, expressive, and phonology factors created for this study. We found that nearly half of all the children (46\%) exhibited a combination of receptive and expressive language problems, which is considered serious, as it is more likely to persist over time $\mathrm{e}^{53}$ and in turn is linked to a higher risk of literacy and educational difficulties throughout the school years. ${ }^{54,55}$ Moreover, a majority of those children also exhibited phonology problems (ie, audible phonological speech problems and/or underlying phonological processing difficulties), which are associated with a risk of later literacy problems, particularly so when in combination with other language difficulties. ${ }^{56,57}$ Almost one in four of the children (24\%) showed expressive language problems without receptive language difficulties, and correspondingly $10 \%$ showed the reverse pattern. In addition, for a substantial proportion of the children in each of these two groups, phonology problems were added to the profile. Isolated receptive - sometimes called "silent" - language problems, are easily overlooked but indeed important, as they may impact the child's comprehension of instructions and discourse. A small proportion, $4 \%$, of the children exhibited a language profile of phonology problems only. A majority of the children with moderatesevere language problems (46 of 49) exhibited impaired performance on language measures that mapped on to two 
(eight children) or three (38 children) of the language profile factors. Consequently, most children in the study categorized as exhibiting moderate-severe language problems presented with impairments in both receptive and expressive language, as well as phonology.

Our results confirm other research suggesting that language problems, including phonological speech problems (ie, non-age-appropriate and/or deviant speech-sound patterns), are common in children with ASD without ID, and indeed warrant further attention. ${ }^{3,11}$ Word comprehension was a relative strength in the total group, conforming to the findings of Loucas et al. ${ }^{11}$ Sentence comprehension, word analogies, and grammar, however, posed difficulties for a majority of the children $(53 \%, 52 \%$, and $64 \%$, respectively). Further, $41 \%$ of the children in the total group performed in the impaired range on the nonword-repetition task, reflecting decreased phonological processing ability (ie, the ability to analyze and manipulate word-sound structures). Similarly, previous research has shown difficulty with comprehension of verbal instructions, ${ }^{12}$ semantic organization, ${ }^{2}$ and nonword repetition ${ }^{30,32}$ in children with ASD. Our results also add to the body of research ${ }^{22-25}$ showing that grammatical difficulties are not uncommon in children with ASD.

Quite interestingly, 21\% of the 83 children in our total group, ie, about one in five, exhibited clinically relevant phonological speech problems. As explained in the introduction, phonological speech production may simultaneously be viewed as an aspect of the language domain of phonology and an aspect of speech. In layman's terms, "phonological speech problems" most often are referred to as "speech problems", even though "speech problems" also include other aspects, such as articulation (ie, the motor movements needed to produce speech sounds). Phonological speech problems are common in preschool children, eg, as evident by an estimated prevalence of $13 \%$ in a representative sample of Swedish 4-year-olds. ${ }^{58}$ Our results suggest even higher prevalence of phonological speech problems in children with ASD without ID. Therefore, our study supports the notion summarized in our introduction that phonological speech problems may be more prevalent in children with ASD compared to typically developing peers. At the same time, results are in contrast to the Cleland et $\mathrm{al}^{28}$ study of children with ASD without ID, in which $12 \%$ of participants presented with speech problems. Even though phonological speech errors were not separated from articulatory speech errors in Cleland et al, description of speech errors found was predominantly of a phonological kind. However, one difference compared to the current study is the age range, which was wider in Cleland et al
(5-13 years). The wider age range may have yielded a lower proportion, as audible phonological speech problems tend to decrease with age. ${ }^{16}$ Phonological speech problems often affect the child's intelligibility. As such, "speech problems" may be identified more easily by teachers ${ }^{59}$ and likely also by parents, physicians, and other professionals, possibly concealing expressive and receptive language problems. Therefore, it is crucial to see beyond the child's pronunciation of words to identify such other, more serious language problems. Indeed, in our sample, phonological speech problems were most common in children with a concomitant combination of receptive and expressive language problems, such that $76 \%$ of the children exhibiting phonological speech problems exhibited such a combination.

Comparing our language-profile results with previous research is difficult, because of methodological differences among studies. For example, in a seminal study by Kjelgaard and Tager-Flusberg, ${ }^{10}$ language profiles were presented for a subgroup of children whose nonverbal IQ was described as being "generally" within the normal range. The children's language abilities were classified as impaired $(47 \%)$, borderline $(29 \%)$, or normal (23\%). Although a different methodology was used, these results could perhaps be compared to the $59 \%, 24 \%$, and $17 \%$ of children in our study exhibiting moderate-severe, mild, or no language problems, respectively. However, their subsample did include several children with ID, and the age range (4-14 years) was broader than ours. As Kjelgaard and Tager-Flusberg did not detail proportions of children with impairments in receptive and expressive language and/or phonology, a comparison with our language profiles is not possible. In another example, Chan et al ${ }^{12}$ grouped a subsample of 5- to 6-year-old children with ASD based on language profiles similar to ours, and found $42 \%$ with combined expressive and receptive impairments, 21\% with normal receptive but impaired expressive language, 0 with receptive but no expressive difficulties, and 37\% with normal language. These figures are compared with $46 \%, 24 \%, 10 \%$, and $17 \%$, respectively, in our study. In addition, $\sim 4 \%$ of our children had no receptive or expressive language difficulties, but phonology problems only. However, methodological differences between the two studies are several, eg, four of the 19 children in the Chan et al subsample had an IQ $\leq 70$, the cutoff for "impairment" was lower than ours, phonology measures were not included, and the sample was small and not representative. The third and last example comes from Loucas et al, ${ }^{11}$ who (based on a comprehensive language test) found $57 \%$ with impaired language in their relatively large sample of 9- to 14-year-old children 
with ASD without ID drawn from a population cohort. The proportion of children reported to exhibit impairments in both receptive and expressive language was $32 \%$, which is a smaller share compared to our findings, even though Loucas et al used a lower cutoff for "impairment" (-1.5 SD). Proportions of children exhibiting only receptive or expressive impairments were not detailed. The corresponding proportion of children with normal language (ie, $43 \%$ ) was almost three times as large than in the current study. In addition to using a lower cutoff, the dissimilarity may possibly depend on the different age-groups studied, as their sample likely included children diagnosed with ASD at a later age, many of whom may have gone unnoticed at an early age due to no language problems. Moreover, if phonology had been considered, the proportion with normal language might have been smaller.

Differences in test performance between ASD subgroups in the current study were found for all language measures, except PSPA. In general, performances of the AD and PDD-NOS groups were lower than the AS group, with AFgroup performance falling in between. Further, descriptive analysis of differences in language profiles between ASD subgroups revealed that a majority of the children with AD (70\%) and PDD-NOS (54\%) had combined receptive and expressive language problems with or without phonology problems. In contrast, such a profile was less common for the children with AFs (29\%) and not seen at all in children with AS. Interestingly, $58 \%$ of the children with AS did display some degree of language problems, in particular difficulties with sentence comprehension. Although diagnostic criteria for AS state clinically normal language development, ${ }^{39}$ there is converging evidence for a certain degree of language difficulty (on a group level) in children with AS when assessing more complex language. ${ }^{3}$ Indeed, the language criterion in the DSM-IV is not based on a specific assessment by a speech-language pathologist, but rather reflects more of a "superficial" language ability. Therefore, it should not be surprising that the children with AS also showed some language problems. Lastly, all ASD subgroups were represented in the share of children demonstrating a profile of no language problems according to the test battery used in the present study. The highest proportion of children with no language problems was found in the AS group (42\%) and the lowest in the AD group (5\%, ie, one in 20 children).

As for the relationship between language variables and IQ in our study group, results showed that only 4\%-16\% $\left(r^{2}\right)$ of the variation in the different language scores could be accounted for by PIQ. Moreover, the correlation with
PSPA was the lowest and not statistically significant. These results indicate that language performance in children with ASD without ID can be explained only to a low or very low extent by nonverbal IQ. In addition, results suggest that there was no relationship between PIQ and phonological speech production in this population. Similarly, data from two epidemiological, population-based studies examining profiles of language and nonverbal IQ development showed nonnegligible groups of children who demonstrated language in the normal range (standard score $\geq-1.25 \mathrm{SD}$ ) and low nonverbal IQ (standard score <85). ${ }^{49}$ Explanatory values of VIQ on the variance in language scores were relatively low (10\%-39\%) for all but word analogies (66\%), suggesting that language problems in children with ASD without ID cannot be predicted by a VIQ measure to the extent that one might have expected.

\section{Methodological discussion}

A major advantage of the current study was the large, unselected, community-representative group of children with ASD without ID investigated. To that end, our sample did not include children diagnosed later than age 4.5 years, many of which likely have fewer language problems and thus go undetected longer. Therefore, our study might have found a somewhat higher proportion of children with language problems than a cross-sectional study of 4- to 6-year-old - or older - children with ASD without ID would have. In addition, 14 children in our sample no longer qualified for a definite ASD diagnosis. Excluding them in the analyses would have altered our results by a few percent. Since longitudinal studies of language across the spectrum are lacking and needed, ${ }^{3}$ we considered it important to include the AF group. Although the current study design was not longitudinal per se, the sample originated from a group of children with ASD followed longitudinally. At later school age, as academic and social demands increase, it is not unlikely that some children in the AF group may qualify for an ASD diagnosis once again. ${ }^{60}$ Moreover, children who are diagnosed at a later age and whose language could have appeared to develop typically may have subtler, "unhearable" language difficulties that may be identified as language demands increase. Another advantage of the current study was the broad assessment of language, which included phonology and receptive and expressive language abilities. Moreover, an important contribution of our data is the proportion of children with ASD without ID that demonstrated phonological speech problems, ie, difficulty with speech-sound patterns, affecting their pronunciation of words. Also, the inclusion of phonology 
may have resulted in a higher proportion of children with language problems compared to other studies of the same population that have not usually included phonology. Considering all these aspects, it is interesting that our results compare well to the $57 \%$ with impaired language found in the study of older children (9-14 years) with ASD without ID by Loucas et al. ${ }^{11}$ This comparison holds up also when taking into account the fact that the language measure used in Loucas et al did not include phonology. Excluding the one child who performed in the impaired range on two measures but solely on measures of phonology, $58 \%$ of the children in our sample were classified as having moderate-severe language problems.

\section{Limitation}

A limitation of the current study might have been the use of a range of different tests compared to the use of composite scores from one comprehensive test; however, the tests were chosen based on Swedish availability, participation likelihood of young children with ASD, and coverage of receptive, expressive, and phonology abilities in the limited test time available. To clarify further, the children and their parents had already participated in many treatment sessions and meetings at their preschools and with staff at the ACYC. Moreover, they also participated in a variety of evaluations included in the 2-year follow-up of the cohort, of which the language assessment reported here was a part. These were important aspects that we needed to consider for the recruitment of study participants and language assessments to be conducted. Another aspect we considered was that in general, children with ASD have limited ability to participate in long assessments. We thus had to take into account available test materials and what test battery would be realistic in terms of child (and parent) participation, where the latter had a very high priority. Therefore, the total time taken administering the test battery was crucial. In some cases, we consequently had to choose between obtaining (possibly) higher-quality data and a realistic test time. As an example, the two alternatives that we considered for assessing vocabulary were the SPIQ and the Peabody Picture Vocabulary Test (PPVT) III. ${ }^{41,61}$ Documentation of validity and reliability was better for the PPVT-III than for the SPIQ, but the PPVT-III would have been considerably more time-consuming to administer, and we thus decided to use the SPIQ. The options we had for assessing grammar were of a similar kind. The final selection of subtests included in the test battery was designed to tap into the specific language abilities that we wanted to investigate, at the same time lending a reasonable total testing time.
At the time of the study, there was no comprehensive test adapted into Swedish that covered the language abilities we wanted to examine. Compared to the use of a comprehensive language test, the composition of subtests used in the study may have affected the outcome. However, the fact that the 49 (of 83) children in the study classified as having moderatesevere language problems exhibited impaired performance on two or more of our six measures speaks to the clinical relevance of the children's language difficulties. Moreover, eight of those 49 children performed in the impaired range on measures that mapped onto two and 38 children on measures that mapped onto three of the language-profile factors created for this study.

\section{Clinical implications and conclusion}

Moderate-severe language problems, including phonological speech problems, were common in children with ASD without ID, and these problems occurred across subgroups of ASD diagnoses, though they were less conspicuous in the AS group. The new DSM-5 includes but one diagnostic category, ASD, without any diagnostic subgroups specified; however, the severity of the ASD should be defined, as well as accompanying ID and/or language impairment. ${ }^{62}$ Ours and others' findings highlighting the commonality of language problems in children with ASD without ID, together with the DSM-5 notion, underscore the importance of detailed language assessment by speech-language pathologists as part of ASD diagnostic practice, as well as at follow-ups. Expressive and receptive language and phonology problems, including problems with phonological speech production, detected by a speech-language pathologist's assessment are an important complement to the psychologist's cognitive assessments.

In Sweden, children with ASD without ID most often attend mainstream classes and study according to the regular curriculum. They are not regularly entitled to specific interventions or support when they reach school age, which often leads to lack of adequate assistance. This apprehension was confirmed in a recent follow-up of the present study group, where most parents reported their child receiving insufficient support at school. ${ }^{63}$ Children with ASD without ID thus run the risk of not getting adequate prerequisites for learning, and particularly so if their difficulties with language comprehension and expression and phonology, phonological speech problems included, do not receive sufficient attention. In fact, studies have shown high rates of teacher underidentification and limited understanding of child language problems, risks that perhaps increase even further if the school focuses 
exclusively on the child's autism diagnosis. ${ }^{64}$ Just like children with ASD and ID, children with ASD without ID thus need clinical follow-up during preschool and school age for decisions on whether new assessments and interventions are necessary in regard to their general cognitive ability, speech and language, and behavioral characteristics. In addition, follow-ups should be conducted in collaboration with the school, in order to consider whether the child has an optimal school situation with understanding of the specific educational needs and how pedagogical adjustments and support can best be provided. To sum up, our study underlines the importance of an increased focus on and understanding of the language strengths and difficulties in children with ASD without ID, since - in addition to intellectual level - language skill is a crucial factor for long-term educational and social outcome.

\section{Acknowledgments}

The authors are grateful to all children who took part in the study. Financial support was given through grants from the Aina Börjesson Foundation (LK, FN), LifeWatch Award, Niclas Öberg Foundation (EF), and Per and Annmari Ahlqvist Foundation (CG).

\section{Author contributions}

LK was involved in study design, data collection, analysis and interpretation of data, and writing the manuscript. EF was involved in study design, interpretation of data, and provided comments on the manuscript. CG was involved in study design and provided comments on the manuscript. FN was involved in study design, data collection, analysis and interpretation of data, and writing the manuscript.

\section{Disclosure}

The authors report no conflicts of interest in this work.

\section{References}

1. Groen W, Zwiers M, Vandergaag R, Buitelaar J. The phenotype and neural correlates of language in autism: An integrative review. Neurosci Biobehav Rev. 2008;32(8):1416-1425.

2. Eigsti I-M, de Marchena AB, Schuh JM, Kelley E. Language acquisition in autism spectrum disorders: A developmental review. Res Autism Spectr Disord. 2011;5(2):681-691.

3. Boucher J. Research review: structural language in autistic spectrum disorder - characteristics and causes. J Child Psychol Psychiatry. 2012; 53(3):219-233.

4. Charman T, Drew A, Baird C, Baird G. Measuring early language development in preschool children with autism spectrum disorder using the MacArthur Communicative Development Inventory (Infant Form). J Child Lang. 2003;30(1):213-236.

5. Hudry K, Leadbitter K, Temple K, et al. Preschoolers with autism show greater impairment in receptive compared with expressive language abilities. Int J Lang Commun Disord. 2010;45(6):681-690.
6. Kover ST, Mcduffie AS, Hagerman RJ, Abbeduto L. Receptive vocabulary in boys with autism spectrum disorder: cross-sectional developmental trajectories. J Autism Dev Disord. 2013;43(11):2696-2709.

7. Luyster RJ, Kadlec MB, Carter A, Tager-Flusberg H. Language assessment and development in toddlers with autism spectrum disorders. J Autism Dev Disord. 2008;38(8):1426-1438.

8. Ellis Weismer S, Lord C, Esler A. Early language patterns of toddlers on the autism spectrum compared to toddlers with developmental delay. J Autism Dev Disord. 2010;40(10):1259-1273.

9. Kwok EYL, Brown HM, Smyth RE, Oram Cardy J, Cardy JO. Metaanalysis of receptive and expressive language skills in autism spectrum disorder. Res Autism Spectr Disord. 2015;9:202-222.

10. Kjelgaard MM, Tager-Flusberg H. An Investigation of Language Impairment in Autism: Implications for Genetic Subgroups. Lang Cogn Process. 2001;16(2-3):287-308.

11. Loucas T, Charman T, Pickles A, et al. Autistic symptomatology and language ability in autism spectrum disorder and specific language impairment. J Child Psychol Psychiatry. 2008;49(11):1184-1192.

12. Chan AS, Cheung J, Leung WWM, Cheung R, Cheung M-Chun. Verbal Expression and Comprehension Deficits in Young Children With Autism. Focus Autism Other Dev Disabl. 2005;20(2):117-124.

13. Kjellmer L, Hedvall $\AA$, Holm A, Fernell E, Gillberg C, Norrelgen F. Language comprehension in preschoolers with autism spectrum disorders without intellectual disability: Use of the Reynell Developmental Language Scales. Res Autism Spectr Disord. 2012;6(3):1119-1125.

14. Åsberg J. Patterns of language and discourse comprehension skills in school-aged children with autism spectrum disorders. Scand J Psychol. 2010;51(6):534-539.

15. Broome K, Mccabe P, Docking K, Doble M. A Systematic Review of Speech Assessments for Children With Autism Spectrum Disorder: Recommendations for Best Practice. Am J Speech Lang Pathol. 2017; 26(3):1011-1029.

16. Paul R, Norbury C. Language disorders from infancy through adolescence: listening, speaking, reading, writing, and communicating. 4th, ed. St. Louis: Elsevier; 2012:401-405.

17. Kjellmer L, Hedvall Å, Fernell E, Gillberg C, Norrelgen F. Language and communication skills in preschool children with autism spectrum disorders: contribution of cognition, severity of autism symptoms, and adaptive functioning to the variability. Res Dev Disabil. 2012;33(1): 172-180.

18. Luyster R, Lopez K, Lord C. Characterizing communicative development in children referred for autism spectrum disorders using the MacArthur-Bates Communicative Development Inventory (CDI). J Child Lang. 2007;34(3):623-654.

19. Tager-Flusberg $H$. The conceptual basis for referential word meaning in children with autism. Child Dev. 1985;56(5):1167-1178.

20. Tager-Flusberg H. Understanding the language and communicative impairments in autism. Int Rev Res Mental Retardation. 2001;23: 185-205.

21. Diehl JJ, Bennetto L, Watson D, Gunlogson C, Mcdonough J. Resolving ambiguity: a psycholinguistic approach to understanding prosody processing in high-functioning autism. Brain Lang. 2008;106(2):144-152.

22. Bartolucci G, Pierce SJ, Streiner D. Cross-sectional studies of grammatical morphemes in autistic and mentally retarded children. J Autism Dev Disord. 1980;10(1):39-50.

23. Howlin $P$. The acquisition of grammatical morphemes in autistic children: a critique and replication of the findings of Bartolucci, Pierce, and Streiner, 1980. J Autism Dev Disord. 1984;14(2):127-136.

24. Park CJ, Yelland GW, Taffe JR, Gray KM. Morphological and syntactic skills in language samples of pre school aged children with autism: atypical development? Int J Speech Lang Pathol. 2012;14(2):95-108.

25. Zhou P, Crain S, Gao L, Tang Y, Jia M. The use of grammatical morphemes by Mandarin-speaking children with high functioning autism. J Autism Dev Disord. 2015;45(5):1428-1436.

26. Ambridge B, Bannard C, Jackson GH. Is grammar spared in autism spectrum disorder? Data from judgments of verb argument structure overgeneralization errors. J Autism Dev Disord. 2015;45(10):3288-3296. 
27. Rapin I, Dunn MA, Dunn MA, Allen DA, Stevens MC, Fein D. Subtypes of language disorders in school-age children with autism. Dev Neuropsychol. 2009;34(1):66-84.

28. Cleland J, Gibbon FE, Peppé SJ, O’Hare A, Rutherford M. Phonetic and phonological errors in children with high functioning autism and Asperger syndrome. Int J Speech Lang Pathol. 2010;12(1):69-76.

29. Shriberg LD, Paul R, Black LM, van Santen JP. The hypothesis of apraxia of speech in children with autism spectrum disorder. J Autism Dev Disord. 2011;41(4):405-426.

30. Riches NG, Loucas T, Baird G, Charman T, Simonoff E. Non-word repetition in adolescents with specific language impairment and autism plus language impairments: a qualitative analysis. J Commun Disord. 2011;44(1):23-36.

31. Whitehouse AJ, Barry JG, Bishop DV. Further defining the language impairment of autism: is there a specific language impairment subtype? J Commun Disord. 2008;41(4):319-336.

32. Williams D, Payne H, Marshall C. Non-word repetition impairment in autism and specific language impairment: evidence for distinct underlying cognitive causes. J Autism Dev Disord. 2013;43(2):404- 417.

33. Billstedt E, Gillberg IC, Gillberg C, Gillberg C. Autism after adolescence: population-based 13- to 22-year follow-up study of 120 individuals with autism diagnosed in childhood. J Autism Dev Disord. 2005;35(3): 351-360.

34. Magiati I, Tay XW, Howlin P, Cognitive HP. Cognitive, language, social and behavioural outcomes in adults with autism spectrum disorders: a systematic review of longitudinal follow-up studies in adulthood. Clin Psychol Rev. 2014;34(1):73-86.

35. Norrelgen F, Fernell E, Eriksson M, et al. Children with autism spectrum disorders who do not develop phrase speech in the preschool years. Autism. 2015;19(8):934-943.

36. Fernell E, Hedvall A, Norrelgen F. Developmental profiles in preschool children with autism spectrum disorders referred for intervention. Res Devel Disab. 2010;31(3):790-799.

37. Fernell E, Hedvall Å, Westerlund J, et al. Early intervention in 208 Swedish preschoolers with autism spectrum disorder. A prospective naturalistic study. Res Dev Disabil. 2011;32(6):2092-2101.

38. Wechsler D. Wechsler Preschool and Primary Scale of Intelligence, Revised, Swedish Version; 1999. Stockholm: Psykologiförlaget; 2004.

39. American Psychiatric Association. Diagnostic and Statistical Manual of Mental Disorders. 4th ed. Washington, DC: APA; 1994.

40. Edwards S, Fletcher P, Garman M, Hughes A, Letts C, Sinka I. The Reynell Developmental Language Scales III. Windsor, Berks, UK: The nferNelson Publishing Company Ltd; 1997.

41. Rydberg S, Höghielm R. SPIQ: Snabbt Performancetest På Intelligence (IQ). Stockholm: Psykologiförlaget; 1974.

42. Kirk SA, Holmgren B, McCarthy JJ, Kirk WD. ITPA: Illinois Test of Psycholinguistic Abilities. Protokoll. [Ny utg] ed. Stockholm: Psykologiförlaget; 2000.

43. Salameh EK, Hakansson G, Nettelbladt U. Developmental perspectives on bilingual Swedish-Arabic children with and without language impairment: a longitudinal study. Int J Language Commun Disorders. 2004;39(1):65-91.

44. Nyman A.Nonordsrepetition, Nonordsdiskrimination Och Metafonologisk Förmåga. Finns Det Några Samband Och Hur Påverkar Nonordens Stavelselängd? Lund, Dept. of Logopedics, Phoniatrics \& Audiology, Lund University; 1999.
45. Renfrew CE. Bus Story Test: A Test of Narrative Speech. 4th ed. Milton, Keynes, UK: Speechmark; 1997.

46. Svensson Y, Tuominen-Eriksson AM. Buss-sagan Svensk Översättning Och Bearbetning. Göteborg: Specialpedagogiska Institutet Läromedel; 2002.

47. Grunwell P. Clinical Phonology. 2nd ed. London: Croom Helm; 1987.

48. Bjar L. Orden tar form - om barns uttalsutveckling. In: Bjar L, Liberg C, editors. Barn Utvecklar Sitt Språk. Lund: Studentlitteratur: 2003.

49. Reilly S, Tomblin B, Law J, et al. Specific language impairment: a convenient label for whom? Int J Lang Commun Disord. 2014;49(4): 416-451.

50. Pienemann M. Cross-Linguistic Aspects of Processability Theory. Amsterdam: Benjamin; 2005.

51. Nettelbladt U, Salameh E-K, editors. Språkutveckling Och Språkstörning Hos Barn. Studentlitteratur; 2007.

52. Hansson K, Nettelbladt U. GRAMBA: Grammatiktest för Barn. Skivarp: Pedagogisk design; 2004.

53. Snowling MJ, Bishop DV, Stothard SE, Chipchase B, Kaplan C. Psychosocial outcomes at 15 years of children with a preschool history of speech-language impairment. J Child Psychol Psychiatry. 2006; 47(8):759-765.

54. Stothard SE, Snowling MJ, Bishop DV, Chipchase BB, Kaplan CA. Language-impaired preschoolers: a follow-up into adolescence. J Speech Lang Hear Res. 1998;41(2):407-418.

55. Catts HW, Fey ME, Tomblin JB, Zhang X. A longitudinal investigation of reading outcomes in children with language impairments. $J$ Speech Lang Hear Res. 2002;45(6):1142-1157.

56. Boets B, de Smedt B, Cleuren L, Vandewalle E, Wouters J, Ghesquière P. Towards a further characterization of phonological and literacy problems in Dutch-speaking children with dyslexia. $\mathrm{Br} J \mathrm{Dev}$ Psychol. 2010;28(Pt 1):5-31.

57. Pennington BF, Bishop DV. Relations among speech, language, and reading disorders. Annu Rev Psychol. 2009;60:283-306.

58. Westerlund M. Barn Med Tal-Och Språkavvikelser: En Prospektiv Longitudinell Epidemiologisk Studie Av En Arskull Uppsalabarn Vid 4, 7 Och 9 Ars Alder. Uppsala, Uppsala Universitet; 1994.

59. Antoniazzi D, Snow P, Dickson-Swift V. Teacher identification of children at risk for language impairment in the first year of school. Int J Speech Lang Pathol. 2010;12(3):244-252.

60. Olsson MB, Westerlund J, Lundström S, Giacobini M, Fernell E, Gillberg C. "Recovery" from the diagnosis of autism - and then? Neuropsychiatr Dis Treat. 2015;11:999-1005.

61. Dunn LM, Dunn LM. Peabody Picture Vocabulary Test-III. Circle, Pines, MN: American Guidance Service; 1997.

62. American Psychiatric Association. Diagnostic and Statistical Manual of Mental Disorders. 5th ed. Washington, DC: APA; 2013.

63. Barnevik Olsson M, Lundström S, Westerlund J, Giacobini MB, Gillberg C, Fernell E. Preschool to School in Autism: Neuropsychiatric Problems 8 Years After Diagnosis at 3 Years of Age. J Autism Dev Disord. 2016;46(8):2749-2755.

64. Dockrell JE, Lindsay G. Children with specific speech and language difficulties - the teachers' perspective. Oxford Rev Educ. 2001;27(3) 369-394.
Neuropsychiatric Disease and Treatment

\section{Publish your work in this journal}

Neuropsychiatric Disease and Treatment is an international, peerreviewed journal of clinical therapeutics and pharmacology focusing on concise rapid reporting of clinical or pre-clinical studies on a range of neuropsychiatric and neurological disorders. This journa is indexed on PubMed Central, the 'PsycINFO' database and CAS,

\section{Dovepress}

and is the official journal of The International Neuropsychiatric Association (INA). The manuscript management system is completely online and includes a very quick and fair peer-review system, which is all easy to use. Visit http://www.dovepress.com/testimonials.php to read real quotes from published authors. 